\title{
Livedo Reticularis Associated with COVID-19
}

\author{
Toshinori Sahara and Kazuhisa Yokota
}

Key words: COVID-19, livedo reticularis

(Intern Med 61: 441, 2022)

(DOI: 10.2169/internalmedicine.8033-21)

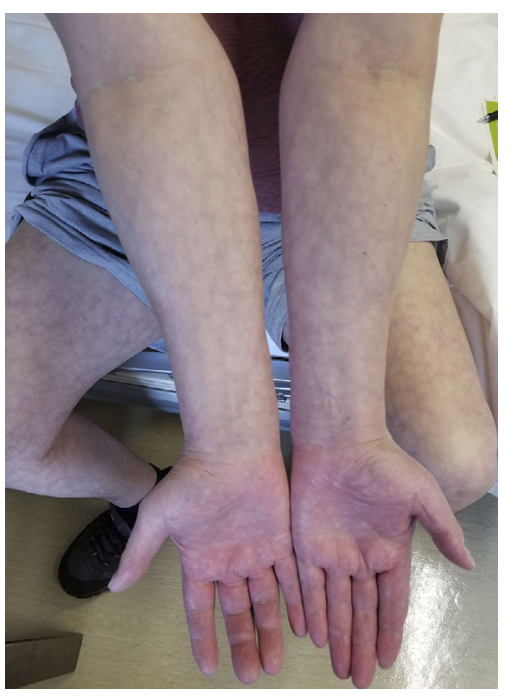

Picture 1.

A 57-year-old man was admitted in order to be treated for coronavirus disease 2019 (COVID-19). He had no past medical history, taking no medications or supplements. He has no history of COVID-19 vaccination. His main symptom was fever for three consecutive days. On admission, he also complained of mottled skin on his extremities appeared in the morning of the day before admission (Picture 1, 2). His vital signs were stable and laboratory data did not show any blood coagulation abnormalities. His symptoms gradually improved as he demonstrated mild COVID-19 and consequently he was discharged on day 5 after hospitalization while his skin lesions still had not completely disappeared.

Freeman et al. reported that livedo reticularis-like lesions were observed in $3.5 \%$ of all cutaneous manifestations with COVID-19 (1). Since livedo reticularis is caused by a disturbance of the blood flow, it reminds us of the hypercoagulable state among COVID-19 patients. However, most of the livedo reticularis-like lesions associated with COVID-19 tend to be mild and transient, which is not associated with

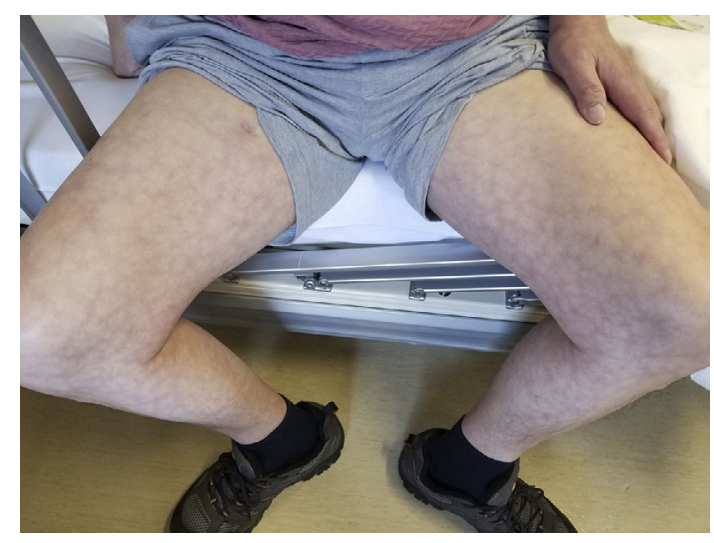

Picture 2.

any thromboembolic events (2). When we encounter livedo reticularis-like lesions associated with COVID-19, we should observe it carefully but not administer any excessive treatments.

The authors state that they have no Conflict of Interest (COI).

\section{Acknowledgement}

We thank the entire staff at the COVID-19 ward in Ebara Hospital for their assistance in the clinical management.

\section{References}

1. Freeman EE, McMahon DE, Lipoff JB, et al. The spectrum of COVID-19-associated dermatologic manifestations: an international registry of 716 patients from 31 countries. J Am Acad Dermatol 83: 1118-1129,

2. Genovese G, Moltrasio C, Berti E, Marzano AV. Skin manifestations associated with COVID-19: current knowledge and future perspectives. Dermatology 237: 1-12, 2021.

The Internal Medicine is an Open Access journal distributed under the Creative Commons Attribution-NonCommercial-NoDerivatives 4.0 International License. To view the details of this license, please visit (https://creativecommons.org/licenses/ by-nc-nd/4.0/).

Department of Infectious Diseases, Ebara Hospital, Tokyo Metropolitan Health and Hospital Corporation, Japan Received: May 26, 2021; Accepted: September 27, 2021; Advance Publication by J-STAGE: November 13, 2021 Correspondence to Dr. Toshinori Sahara, saharakotetu@gmail.com

(C) 2022 The Japanese Society of Internal Medicine. Intern Med 61: 441, 2022 